\title{
Correlation between Electrical Properties and Potentiometric Response of CS-Clay Nanocomposite Membranes
}

\author{
M. Oviedo Mendoza, ${ }^{1}$ O. Arias de Fuentes, ${ }^{1,2}$ E. Prokhorov, \\ G. Luna Barcenas, ${ }^{1}$ and E. Padilla Ortega ${ }^{1}$ \\ ${ }^{1}$ CINVESTAV-Unidad Querétaro, Libramiento Norponiente 2000, Fraccionamiento Real de Juriquilla, \\ 76230 Querétaro, QRO, Mexico \\ ${ }^{2}$ Instituto de Ciencia y Tecnología de Materiales (IMRE-UH), Universidad de La Habana, Zapata y G, Vedado, CP 10400, \\ La Habana, Cuba
}

Correspondence should be addressed to E. Prokhorov; prokhorov@qro.cinvestav.mx

Received 22 January 2015; Accepted 4 May 2015

Academic Editor: Luigi Nicolais

Copyright (C) 2015 M. Oviedo Mendoza et al. This is an open access article distributed under the Creative Commons Attribution License, which permits unrestricted use, distribution, and reproduction in any medium, provided the original work is properly cited.

The aim of this work is to study the relationship between electrical, structure, and potentiometric response to nitrate anions using Ion Selective Electrodes (ISE). These ISE are based on chitosan-montmorillonite nanocomposite membranes with different content of montmorillonite. Membrane properties have been studied using SEM, FTIR, and impedance spectroscopy measurements. With the advent of impedance spectroscopy one is allowed to obtain the DC conductivity dependence on montmorillonite concentration and the percolation threshold. Additionally, the potentiometric response to nitrate anions of ISE based on chitosanclay nanocomposite has been investigated. It is shown that the properties and performance of these membrane electrodes depend upon the clay wt\% and that the best sensitivity to nitrate ions (with detection limit $7 \times 10^{-5} \mathrm{M}$ ) is obtained near the percolation concentration $c a .8 \pm 2.5 \mathrm{wt} \%$ of clay. This observation is traceable to higher clay content (higher agglomeration) that tends to decrease the intercalation and absorption of the number of chitosan chains in the interlayer space of montmorillonite.

\section{Introduction}

Chitosan (CS) is a natural biopolymer that has several favorable properties such as biodegradability, biocompatibility, and nontoxicity; it exhibits good solubility in acidic aqueous solutions. Chitosan is easily processed into films, gels, nanofibers, nanoparticles, and scaffolds such that it is advantageously used in tissue engineering, controlled drug delivery, biotechnology, and sensor applications [1, 2]. The last application is based upon chitosan's ability to bind to some molecules or ions by both reactive groups: $-\mathrm{NH}_{3}{ }^{+}$and $-\mathrm{OH}^{-}[3,4]$. However, this biopolymer has some processing disadvantages such as poor mechanical properties and high water absorption [5]. To overcome these disadvantages many reported works have proposed adding metal and nonmetal nanoparticles. In this regard, mineral clays are readily available and offer the possibility to interact with different ions; they offer an interesting way to develop new organic-inorganic hybrid materials. Layered silicate clays such as montmorillonite (MMT) have been widely studied due to their availability and low cost [6].

Chitosan monomer possesses both amino and hydroxyl functional groups; these functional groups can form hydrogen bonding with the silicate hydroxylated edge groups, which leads to strong interaction between matrix and silicate layers [7]. Other authors proposed that in CS-clay nanocomposites electrostatic interactions dominate between the $-\mathrm{NH}_{3}{ }^{+}$groups in the chitosan chain and the negative sites in the clay [8]. Such strong interaction between chitosan chain and clay forms flocculated structure of nanocomposite.

CS-clay nanocomposites have mostly been reported for heavy metals adsorption in aqueous solution [9-12]. The 
mechanism for ion metal adsorption in composites is related to complexation with amine sites and hydroxyl groups and absorption on clay due to ion exchange [10].

Exploiting the reactivity of chitosan's functional groups offers the possibility to use chitosan-clay nanocomposites for anion detection $[13,14]$. Chitosan chains are absorbed on the silicate with a mono- or bilayer configuration as a function of chitosan concentration in the clay suspension. When chitosan is in excess and in acidic aqueous media, the protonated amino groups of a second chitosan layer that do not interact with the clay layer remain available as anionexchange sites such that nanocomposites become suitable systems for the detection of anions. MMT is a fine-grained clay with a great expansive capacity. Therefore MMT could be used as low cost hybrid nanocomposites with important application as membranes in Ion Selective Electrodes (ISE) for anions detection.

In this regard it is very important to choose an optimal CS-clay concentration to obtain an ISE with the best response and detection limits. The determination of this optimal CS-clay relationship is nontrivial since one must take into account the exact cation exchange capacity (CEC) of the clay (which has been used for preparation of nanocomposites) and the exact deacetylation degree and molecular weight of CS.

A correlation between electrical properties, structure, and antibacterial properties of chitosan-silver nanoparticles has previously been reported [15]. However, there are no reports, to the best of our knowledge, on the correlation between electrical properties and potentiometric anion response of CS-clay nanocomposite membranes.

It is noteworthy that nitrate determination is very important when considering that human ingestion of nitrate at levels above $10^{-4} \mathrm{M}$ has adverse health effects mainly on infants and children. Infants of age of $0-3$ months are at highest risk because their normal intestinal flora contribute to the generation of methemoglobin; older children and adults can also experience the same problem, but at higher concentrations of nitrate. Exposure to higher levels of nitrate has been associated with increased incidence of cancer in adults and possible increasing incidence of brain tumors, leukemia, and others sickness. For these reasons it is very important to control the nitrate concentration levels in water $[16,17]$.

The aim of this work is to study the relationship between electrical, structure, and potentiometric response to nitrate anions of chitosan-MMT nanocomposite that offer a promising, eco-friendly, and low cost material for ISE membranes.

\section{Materials and Methods}

2.1. Chemicals. CS medium molecular weight (ca. $350 \mathrm{kDa})$ with a deacetylation degree $\geq 85 \%$ was purchased from Aldrich. Sodium bentonite from Cuencame Sonora, Mexico, was supplied from FEMISA SA de CV. Glacial Acetic Acid was purchased from JT Baker. $\mathrm{Cu}\left(\mathrm{NO}_{3}\right)_{2} \cdot 2.5\left(\mathrm{H}_{2} \mathrm{O}\right)(\geq 98 \%)$, $\mathrm{NaF}$ (ACS grade 99\%), and $\mathrm{NaCl}$ (99.9\%) were from JT Baker and $\mathrm{K}_{2} \mathrm{Cr}_{2} \mathrm{O}_{7}$ (ACS grade) and $\mathrm{Na}_{2} \mathrm{SO}_{4}\left(\geq 98.0 \%\right.$ ) and $\mathrm{NaNO}_{3}$ $(\geq 99 \%)$ were from Aldrich and were used as received. Fresh deionized water with a resistivity of $18 \mathrm{M} \Omega \cdot \mathrm{cm}$ was used in all the tests.

2.2. Homoionic Montmorillonite. Homoionic montmorillonite was obtained by ionic exchange with $\mathrm{NaCl}$ (2 M) followed by washing it with deionized water until reaching a chloride-free clay. A test with $\mathrm{AgNO}_{3}(0.1 \mathrm{M})$ and potassium dichromate as indicator was used to confirm that there is no presence of chloride. Clay was dried and grounded to 350 meshes. The cation exchange capacity was also calculated as $140 \mathrm{meq} / 100 \mathrm{~g}$ by using the acetate method [18].

2.3. CS-MMT Nanocomposites Preparation. CS-montmorillonite nanocomposites were prepared by dispersing montmorillonite suspension into CS acidic solution under magnetic stirring. Several samples were prepared by varying the weight percent relationship between clay and dry-based CS. $\mathrm{pH}$ of the CS solution was adjusted to 5.0 with $\mathrm{NaOH}(1 \mathrm{M})$; this solution was added slowly to the clay suspension. Then the mixture was magnetically stirred for 4 hours at $50^{\circ} \mathrm{C}$. Films were prepared by solving cast method.

2.4. Electrode Preparation. CS-clay nanocomposite membranes have been obtained by deposition of $80 \mu \mathrm{L}$ CSmontmorillonite solutions on the polished surface of homemade solid contact electrodes based on graphite-epoxy and left to dry at room temperature.

2.5. CS-MMT Nanocomposite Characterization. The chemical structure of CS-MMT films was analyzed by FourierTransform Infrared spectroscopy (FTIR) technique, in a Perkin Elmer Spectrum 100 spectrophotometer, using ATR and diffuses reflectance techniques. XRD analysis was made by X-ray diffractometer RIGAKU Dmax 2100 using $\mathrm{Cu} K_{\alpha}$ detector, $K_{\alpha 1}=1.5406 \AA$. CS-MMT film's morphology was analyzed by a JXA-8530F Field Emission Electron Probe Microanalyzer (EMPA).

2.6. Electrical Characterization. Impedance measurements were performed on CS-MMT films in a vacuum cell at $27^{\circ} \mathrm{C}$ in the frequency range from $40 \mathrm{~Hz}$ to $110 \mathrm{MHz}$ using an Agilent Precision Impedance Analyzer 4294A. For pure MMT, pellets of $1 \mathrm{~cm}$ of diameter were prepared. A thin layer of gold was vacuum-deposited onto both film sides to serve as electrodes.

2.7. Potentiometric Measurements. To study the anionic response toward nitrate, potentiometric measurements were performed in a pH-meter (420 Aplus, Thermo Orion) adapted with a PC interface for data acquisition. A reference electrode of $\mathrm{Ag} / \mathrm{AgCl}$, supplied from Radiometer ${ }^{\circledR}$, was used. The ionic activity was calculated according to Debye-Hückel approximation using the coefficients published by Meier [18]. The electrode potential was measured over a wide concentration range of nitrate from $9.9 \times 10^{-7} \mathrm{M}$ to $4.7 \times$ $10^{-1} \mathrm{M}$.

Prior to starting the potentiometric measurements, electrodes were conditioned in a $\mathrm{NaNO}_{3}$ solution $10^{-2} \mathrm{M}$ for 


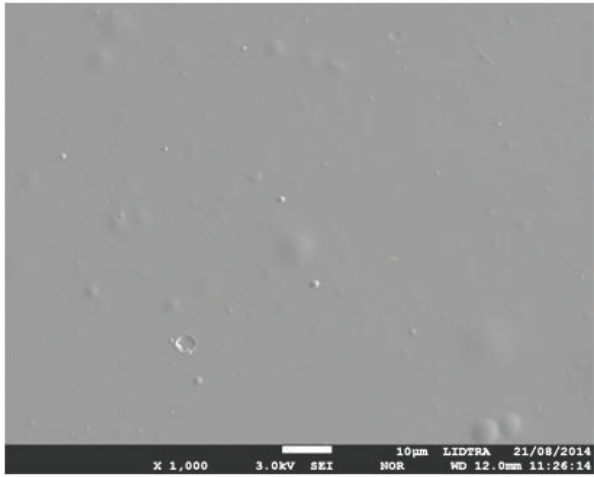

CS

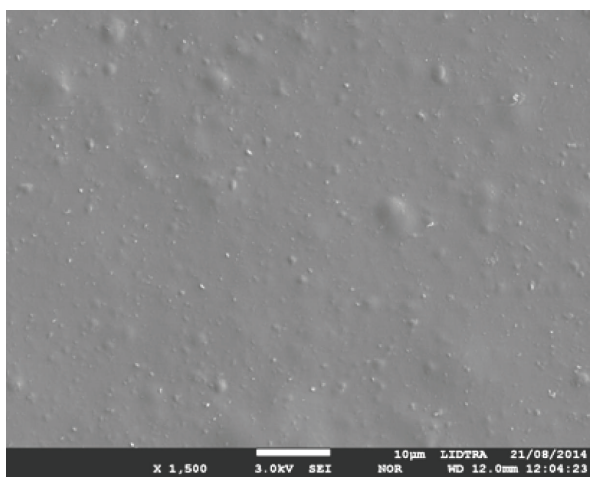

CS $+10 \%$ clay

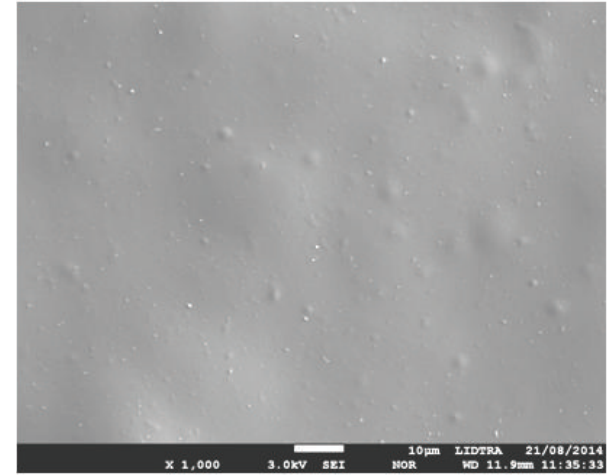

CS $+5 \%$ clay

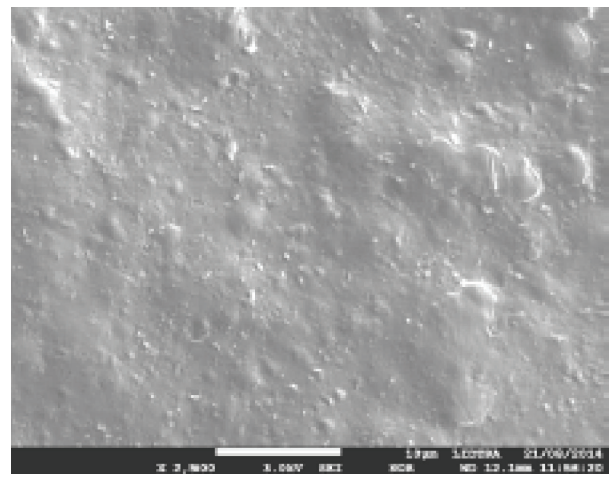

CS $+40 \%$ clay

FIGURE 1: SEM images of CS-MMT composites prepared with different clay wt\%.

a minimum of one hour. Electrodes were kept in $\mathrm{NaNO}_{3}$ solution when not in use.

\section{Results and Discussion}

3.1. CS-Clay Nanocomposite Characterization. Figure 1 shows SEM micrographs of CS-MMT composites films with different $w \mathrm{t} \%$ of clay. Representative SEM images recorded from composites show the homogeneous distribution of clay in the chitosan matrix; however, at high concentration (ca. $40 \mathrm{wt} \%$ ) agglomeration of MMT particles is observed.

FTIR spectra of chitosan clay nanocomposites films with different wt\% of MMT are shown in Figure 2. Nanocomposite's stretching vibrations are those related to CS and the montmorillonite spectra. The most important bands to note are the amino and the $\mathrm{Si}-\mathrm{O}$ groups on the outermost montmorillonite structure. The shifted bands of amino groups at $1549 \mathrm{~cm}^{-1}$ and those at $1021-1080 \mathrm{~cm}^{-1}$ associated with $\mathrm{Si}-\mathrm{O}$ groups of clay confirm electrostatic (or hydrogen bonding) interaction between $\mathrm{NH}_{3}{ }^{+}$and the negative charged sites of clay.

The band at $1150 \mathrm{~cm}^{-1}$ can be associated with the $\mathrm{C}-\mathrm{O}-\mathrm{C}$ groups present in the glucopyranose bond and the one in the ring. The bands at $1080-1025 \mathrm{~cm}^{-1}$ are attributed to the $v_{\mathrm{CO}}$ of the ring $\left(-\mathrm{COH}, \mathrm{C}-\mathrm{O}-\mathrm{C}\right.$, and $\left.-\mathrm{CH}_{2} \mathrm{OH}\right)$. These bands are associated with hydrogen bonding between the free groups $-\mathrm{OH}$ of the $\mathrm{Al}-\mathrm{OH}$ and/or $\mathrm{Si}-\mathrm{OH}$ of the nanocomposite.

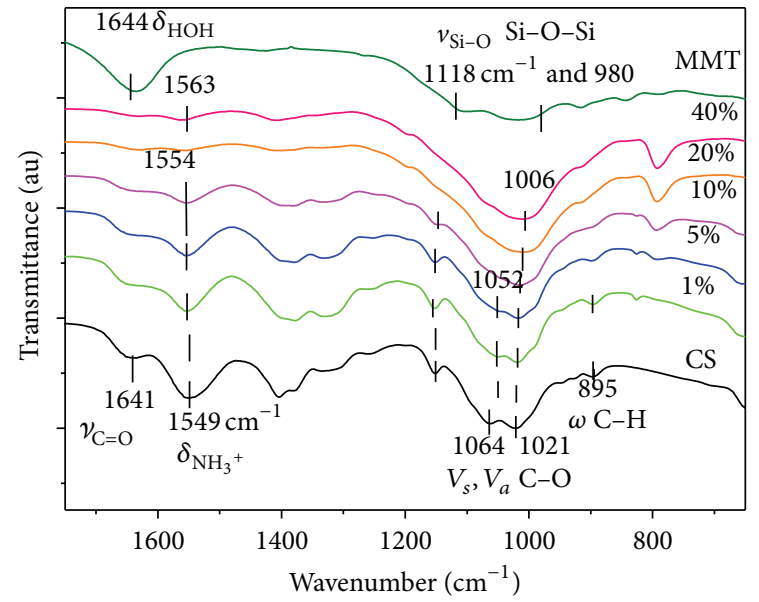

FIGURE 2: FTIR spectra of chitosan clay nanocomposites films obtained at different wt $\%$ montmorillonite.

These results strongly suggest that CS is intercalated between the layers of the montmorillonite.

$\mathrm{XRD}$ measurements confirm that the crystalline phase of the clay corresponds to a Montmorillonite-14 $\AA$ (MMT) with a chemical formula of $\mathrm{Na}_{0.3}(\mathrm{Al}, \mathrm{Mg})_{2} \mathrm{Si}_{4} \mathrm{O}_{10}(\mathrm{OH})_{2 x} \mathrm{H}_{2} \mathrm{O}$ with presence of cristobalite and quartz. XRD measurements (Figure 3) show the peak of montmorillonite corresponding to the main plane (001) at $c a .6 .5^{\circ}$ of $2 \theta$ which is in agreement 


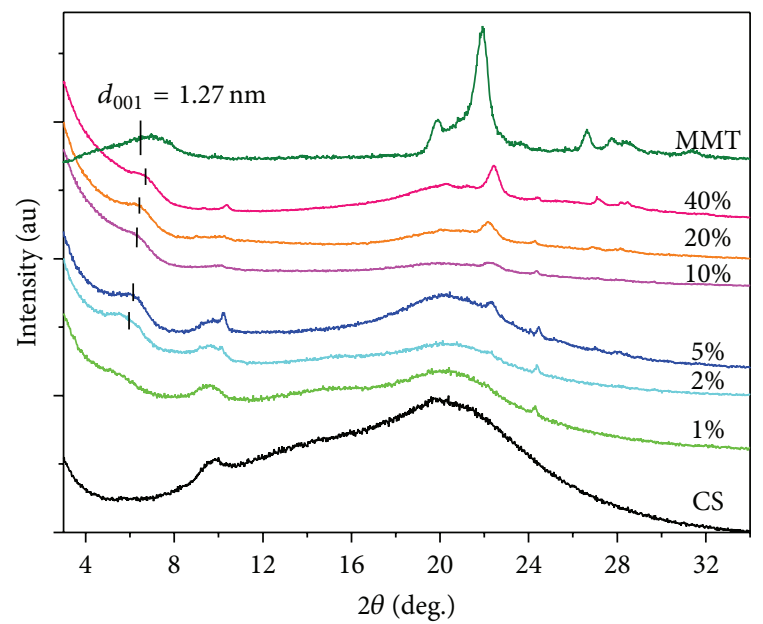

FIGURE 3: XRD patterns of chitosan and CS-MMN composites with different concentrations of montmorillonite indicated on the graph.

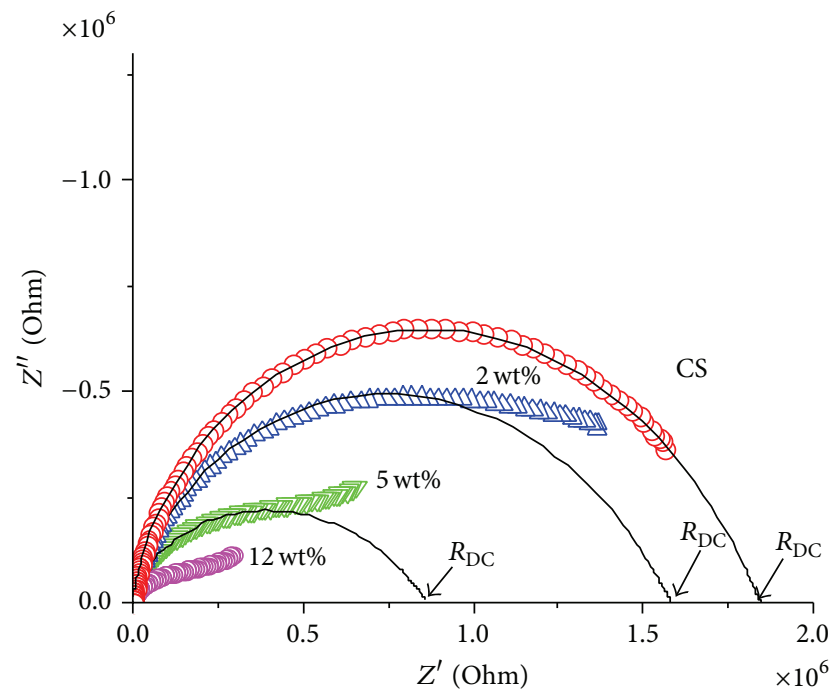

FIGURE 4: Impedance plots of CS and CS-MMT nanocomposites with different concentration of montmorillonite (indicated on the graph).

with previous reports $[19,20]$. The shifting to lower $2 \theta$ degree of this plane indicates intercalation of chitosan between the layered structures of the montmorillonite.

Both FTIR and XRD measurements confirm the formation of bilayer CS-MMT composite and intercalation of chitosan between the layered structures of the montmorillonite.

3.2. Electrical Characterization. Figure 4 shows experimental impedance spectra of CS and CS-MMT nanocomposite (open symbols) and results of fitting (continuous lines) using Cole-Cole depress semicircle [20]. Data fitting of CS films can be well-described using one depressed semicircle. In contrast, in the impedance spectra of CS-MMT composites one can observe a deviation from semicircle due to Maxwell-WagnerSillars interfacial polarization. This polarization occurs in

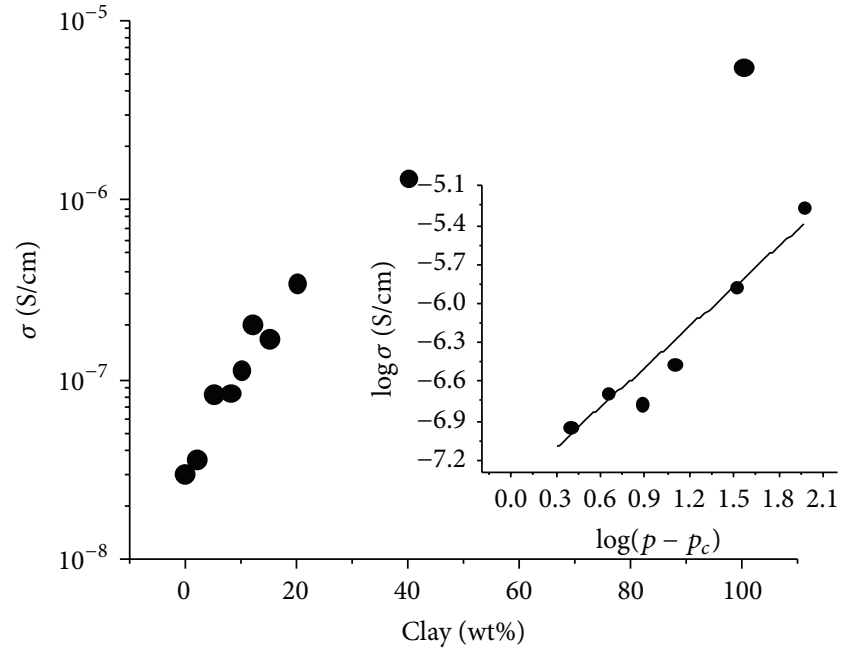

FIGURE 5: DC conductivity of CS-clay films as a function of the clay wt $\%$. Insert shows the log-log dependence of the conductivity of the CS composites on $\left(p-p_{c}\right)$.

heterogeneous systems as a result of accumulation of charge at the interfaces of the phases and it is observed as additional not-resolved semicircle in the low frequency range [20]. Considering the above analysis to determine DC conductivity of CS-MMT films, data fitting has been only done for the high frequency depressed semicircle that does not include interfacial polarization effects.

The DC conductivity $\left(\sigma_{\mathrm{DC}}\right)$ values of pure CS and clay composites were calculated by dielectric measurements using the methodology previously described by our group [21]. The DC resistance $\left(R_{\mathrm{DC}}\right)$ was obtained from the intersection of the semicircle and the real-part axis on the impedance plane (at $Z^{\prime \prime}=0$ ) as it is shown in Figure $4 . \sigma_{\mathrm{DC}}$ can be calculated by the following relationship: $\sigma_{\mathrm{DC}}=d /\left(R_{\mathrm{DC}} \times A\right)$ where $d$ is film thickness and $A$ is the area of the film, respectively.

Figure 5 shows the plots of the DC electrical conductivity obtained from impedance at the room temperature measurements as a function of the clay wt $\%$. An abrupt increasing of conductivity with increasing of clay wt $\%$ and a subsequent saturation is typically observed for percolation phenomena. In the vicinity of the percolation threshold a simple power law describes the DC conductivity as follows [22]:

$$
\sigma \propto\left(p-p_{c}\right)^{t} \quad \text { for } p>p_{c}
$$

where $p$ is the wt $\%$ of conductivity clay phase, $p_{c}$ is the critical clay concentration at the percolation threshold, and $t$ is a critical exponent that only depends on the dimensionality of the percolation system. Insert in Figure 5 represents double $\log -\log$ plot of the experimental data presented in Figure 5 as function of $\left(p-p_{c}\right)$, which according to (1) must demonstrate line dependence. The least-square fitting analysis according to (1) results in a percolation threshold of $(8 \pm 2.5) \mathrm{wt} \%$ of clay.

3.3. Potentiometric Response. Potentiometric responses to nitrate anions obtained using Ion Selective Electrodes (ISE) 


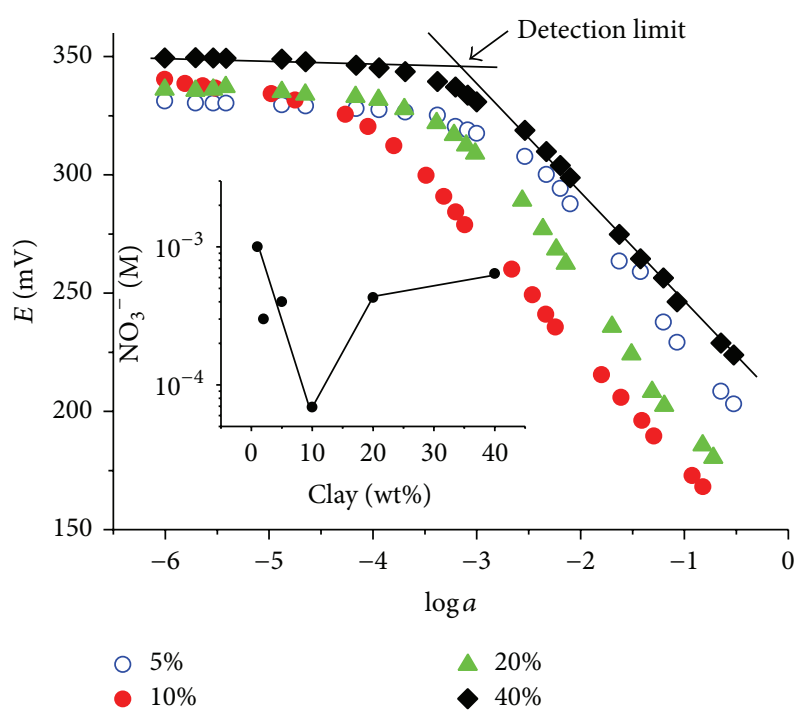

FIGURE 6: Potentiometric response to nitrate of ISE based on chitosan-clay composite membranes with different clay concentrations. Insert shows dependence of detection limit of ISE on the concentration of clay in membranes.

based on CS-MMT membranes with different concentration of clay are shown in Figure 6. It is noteworthy that all curves exhibit a linear response for nitrate ions in a wide concentration range between $c a .10^{-5} \mathrm{M}$ and $10^{-1} \mathrm{M}$ with a near Nernstian slope in the range from -49 to $-54 \mathrm{mV} / \mathrm{dec}$. The detection limits values for the ISE, calculated from the graph, for different clay concentrations depend upon the MMT concentration in the membrane. Insert in Figure 6 shows the dependence of detection limit on the concentration of clay. It can be seen from this graph that the best detection value $\left(7 \times 10^{-5} \mathrm{M}\right)$ for nitrate ions is attained in membranes with $10 \mathrm{wt} \%$ of clay. This value correlates well with percolation threshold ( $8 \pm 2.5 \mathrm{wt} \%$ of clay) discussed in the previous section.

The sensitivity of CS-MMT sensors toward anions is related to the particularly extended conformation of the biopolymer bilayer in the clay interlayer space [13]. At low concentration of clay the number of the chitosan chains (which are responsible for sensibility of nanocomposite toward nitrate ions) in the clay interlayer space is low as result relative low sensitivity is observed. With increasing wt\% of clay, sensitivity must increase as is shown in insert of Figure 6 (below the percolation concentration). The most important question is why sensitivity at the clay concentration higher than the percolation threshold again decreases? To address this question we now discuss conductivity measurements.

Conductivity of montmorillonite $\left(6 \times 10^{-6} \mathrm{~S} / \mathrm{cm}\right)$ is 300 times higher than conductivity of pure chitosan $(2 \times$ $\left.10^{-8} \mathrm{~S} / \mathrm{cm}\right)$. Therefore, the CS-MMT nanocomposites can be represented as chitosan dielectric matrix with conductivity clay inclusions. At the percolation concentration a physical path between conductivity clay inclusions is formed through which the current can flow and at higher clay concentration agglomeration of clay takes place (see Figure 1). These effects
TABLE 1: Potentiometric selectivity coefficients for nitrate ISE based on CS-MMT composite membrane.

\begin{tabular}{lc}
\hline Interfering ions & $K^{\text {pot }}$ \\
\hline $\mathrm{COOH}^{-}$ & 0.526 \\
$\mathrm{~F}^{-}$ & 0.328 \\
$\mathrm{SO}_{4}{ }^{2-}$ & 0.068 \\
$\mathrm{Cr}_{2} \mathrm{O}_{7}{ }^{2-}$ & 0.0185 \\
$\mathrm{Fe}(\mathrm{CN})_{6}{ }^{3-}$ & 0.0076 \\
\hline
\end{tabular}

decrease intercalation and absorption of number of chitosan chains in the interlayer space of montmorillonite by ionexchange mechanism and decrease sensitivity of membranes.

3.4. Selectivity. An important analytical factor for sensors application is their selectivity. Therefore potentiometric selectivity coefficients $\left(K^{\mathrm{pot}}\right)$ for different monovalent, divalent, and trivalent anions were determined by the separate solutions method (SSM) [23], using the ISE based on CS-MMT composite membrane. The studies were performed at $10^{-3} \mathrm{M}$ of concentration for both interfering and nitrate anions. The obtained $K^{\text {pot }}$ values are shown in Table 1 . It can be seen in the referred table that all $K^{\text {pot }}$ values are smaller than 1; according to International Union of Pure and Applied Chemistry (IUPAC) [23] it means that the ISE responds to nitrate ions more selectively than to interfering ones.

\section{Conclusions}

Chitosan-montmorillonite (CS-MMT) nanocomposites have been synthesized and have been used as membrane for Ion Selective Electrodes (ISE). Properties of membrane have been characterized by FTIR and XRD measurements. Both methods confirm the formation of bilayer CS-MMT nanocomposite and the intercalation of chitosan between the layered structures of the montmorillonite. Using the impedance spectroscopy the values of DC conductivity of CS-MMT films with different content of clay and percolation threshold ( $8 \pm 2.5 \mathrm{wt} \%$ of clay) have been determined. Potentiometric response and detection limit of ISE toward nitrate ions have been evaluated. Results obtained have shown that the best sensitivity to nitrate ions $\left(7 \times 10^{-5} \mathrm{M}\right)$ corresponds to $10 \mathrm{wt} \%$ of clay in nanocomposites. In summary, for the first time the correlation between electrical properties and potentiometric anion response of CS-MMT nanocomposite membranes has been obtained. It was shown that the properties of these membranes depend upon the clay wt\% and the best sensitivity to nitrate ions was observed near the percolation concentration. The proposed mechanism is based upon the following observation: at clay concentrations above the percolation threshold, agglomeration promotes a decrease in the intercalation and absorption of number of chitosan chains, which leads to a decrease of both ionexchange and membranes sensitivity.

The results obtained suggest that CS-MMT membrane is a promising, eco-friendly, and low cost material for nitrate anion ISE detection membrane. Additionally, a method is 
proposed in which the correlation of electrical properties to the sensitivity of sensor could be used for development of other nanocomposites for sensor applications.

\section{Conflict of Interests}

The authors declare that there is no conflict of interests regarding the publication of this paper.

\section{Acknowledgments}

This work was partially supported by CONACYT of México. The authors are grateful to M. A. Hernández Landaverde, R. A. Mauricio Sánchez, and J. A. Muñoz Salas for technical assistance.

\section{References}

[1] T. Jiang, R. James, S. G. Kumbar, and C. T. Laurencin, "Chitosan as a biomaterial: structure, properties, and applications in tissue engineering and drug delivery," in Natural and Synthetic Biomedical Polymers, S. G. K. T. L. Deng, Ed., chapter 5, pp. 91113, Elsevier, Oxford, UK, 2014.

[2] A. Casariego, B. W. S. Souza, M. A. Cerqueira et al., "Chitosan/clay films' properties as affected by biopolymer and clay micro/nanoparticles' concentrations," Food Hydrocolloids, vol. 23, no. 7, pp. 1895-1902, 2009.

[3] K. Ogawa, K. Oka, T. Miyanishi, and S. Hirano, Chitin, Chitosan, and Related Enzymes, Elsevier, 1984.

[4] M. Rinaudo, "Chitin and chitosan: properties and applications," Progress in Polymer Science, vol. 31, no. 7, pp. 603-632, 2006.

[5] M. M. Beppu, R. S. Vieira, C. G. Aimoli, and C. C. Santana, "Crosslinking of chitosan membranes using glutaraldehyde: effect on ion permeability and water absorption," Journal of Membrane Science, vol. 301, no. 1-2, pp. 126-130, 2007.

[6] E. P. Giannelis, "Polymer layered silicate nanocomposites," Advanced Materials, vol. 8, no. 1, pp. 29-35, 1996.

[7] S. F. Wang, L. Shen, Y. J. Tong et al., "Biopolymer chitosan/montmorillonite nanocomposites: preparation and characterization," Polymer Degradation and Stability, vol. 90, no. 1, pp. 123-131, 2005.

[8] N. Bitinis, M. Hernandez, R. Verdejo, J. M. Kenny, and M. A. Lopez-Manchado, "Recent advances in clay/polymer nanocomposites," Advanced Materials, vol. 23, no. 44, pp. 5229-5236, 2011.

[9] M. L. P. Dalida, A. F. V. Mariano, C. M. Futalan, C.-C. Kan, W.-C. Tsai, and M.-W. Wan, "Adsorptive removal of $\mathrm{Cu}(\mathrm{II})$ from aqueous solutions using non-crosslinked and crosslinked chitosan-coated bentonite beads," Desalination, vol. 275, no. 1-3, pp. 154-159, 2011.

[10] F. A. R. Pereira, K. S. Sousa, G. R. S. Cavalcanti, M. G. Fonseca, A. G. de Souza, and A. P. M. Alves, "Chitosan-montmorillonite biocomposite as an adsorbent for copper (II) cations from aqueous solutions," International Journal of Biological Macromolecules, vol. 61, pp. 471-478, 2013.

[11] M. Rhazi, J. Desbrières, A. Tolaimate et al., "Influence of the nature of the metal ions on the complexation with chitosan: Application to the treatment of liquid waste," European Polymer Journal, vol. 38, no. 8, pp. 1523-1530, 2002.
[12] C. M. Futalan, C.-C. Kan, M. L. Dalida, K.-J. Hsien, C. Pascua, and M.-W. Wan, "Comparative and competitive adsorption of copper, lead, and nickel using chitosan immobilized on bentonite," Carbohydrate Polymers, vol. 83, no. 2, pp. 528-536, 2011.

[13] M. Darder, M. Colilla, and E. Ruiz-Hitzky, "Chitosan-clay nanocomposites: application as electrochemical sensors," Applied Clay Science, vol. 28, no. 1-4, pp. 199-208, 2005.

[14] M. O. Mendoza, E. P. Ortega, O. A. de Fuentes, Y. Prokhorov, and J. G. Luna Barcenas, "Chitosan/bentonite nanocomposite: preliminary studies of its potentiometric response to nitrate ions in water," in Proceedings of the 9th IEEE Ibero-American Congress on Sensors (IBERSENSOR), pp. 1-4, Bogota, Colombia, October 2014.

[15] E. Prokhorov, J. G. Luna-Bárcenas, J. B. González-Campos, and I. C. Sanchez, "Conductivity mechanisms in a composite of chitosan-silver nanoparticles," Molecular Crystals and Liquid Crystals, vol. 536, no. 1, pp. 24/[256]-32/[264], 2011.

[16] L. Knobeloch, B. Salna, A. Hogan, J. Postle, and H. Anderson, "Blue babies and nitrate-contaminated well water," Environmental Health Perspectives, vol. 108, no. 7, pp. 675-678, 2000.

[17] M. H. Ward and J. D. Brender, "Drinking water nitrate and health," in Encyclopedia of Environmental Health, J. O. Nriagu, Ed., pp. 167-178, Elsevier, Burlington, Mass, USA, 2011.

[18] P. C. Meier, "Two-parameter Debye-Hückel approximation for the evaluation of mean activity coefficients of 109 electrolytes," Analytica Chimica Acta, vol. 136, pp. 363-368, 1982.

[19] M. Darder, M. Colilla, and E. Ruiz-Hitzky, "Biopolymer-clay nanocomposites based on chitosan intercalated in montmorillonite," Chemistry of Materials, vol. 15, no. 20, pp. 3774-3780, 2003.

[20] S. M. L. Silva, C. R. C. Braga, M. V. L. Fook, C. M. O. Raposo, L. H. Carvalho, and E. L. Canedo, "Application of infrared spectroscopy to analysis of chitosan/clay nanocomposites," in Materials Science, Engineering and Technology, T. Theophile, Ed., pp. 43-62, InTech, Rijeka, Croatia, 2012.

[21] J. B. Gonzalez-Campos, E. Prokhorov, G. Iuna-Barcenas, A. Fonseca-Garcia, and I. C. Sanchez, "Dielectric relaxations of chitosan: the effect of water on the $\alpha$-relaxation and the glass transition temperature," Journal of Polymer Science, Part B: Polymer Physics, vol. 47, no. 22, pp. 2259-2271, 2009.

[22] S. Kirkpatrick, "Percolation and conduction," Reviews of Modern Physics, vol. 45, no. 4, pp. 574-588, 1973.

[23] Y. Umezawa, K. Umezawa, K. Tohda, and S. Amemiya, "Potentiometric selectivity coefficients of ion-selective electrodes part I. Inorganic cations (technical report)," Pure and Applied Chemistry, vol. 72, no. 10, pp. 1851-2082, 2000. 

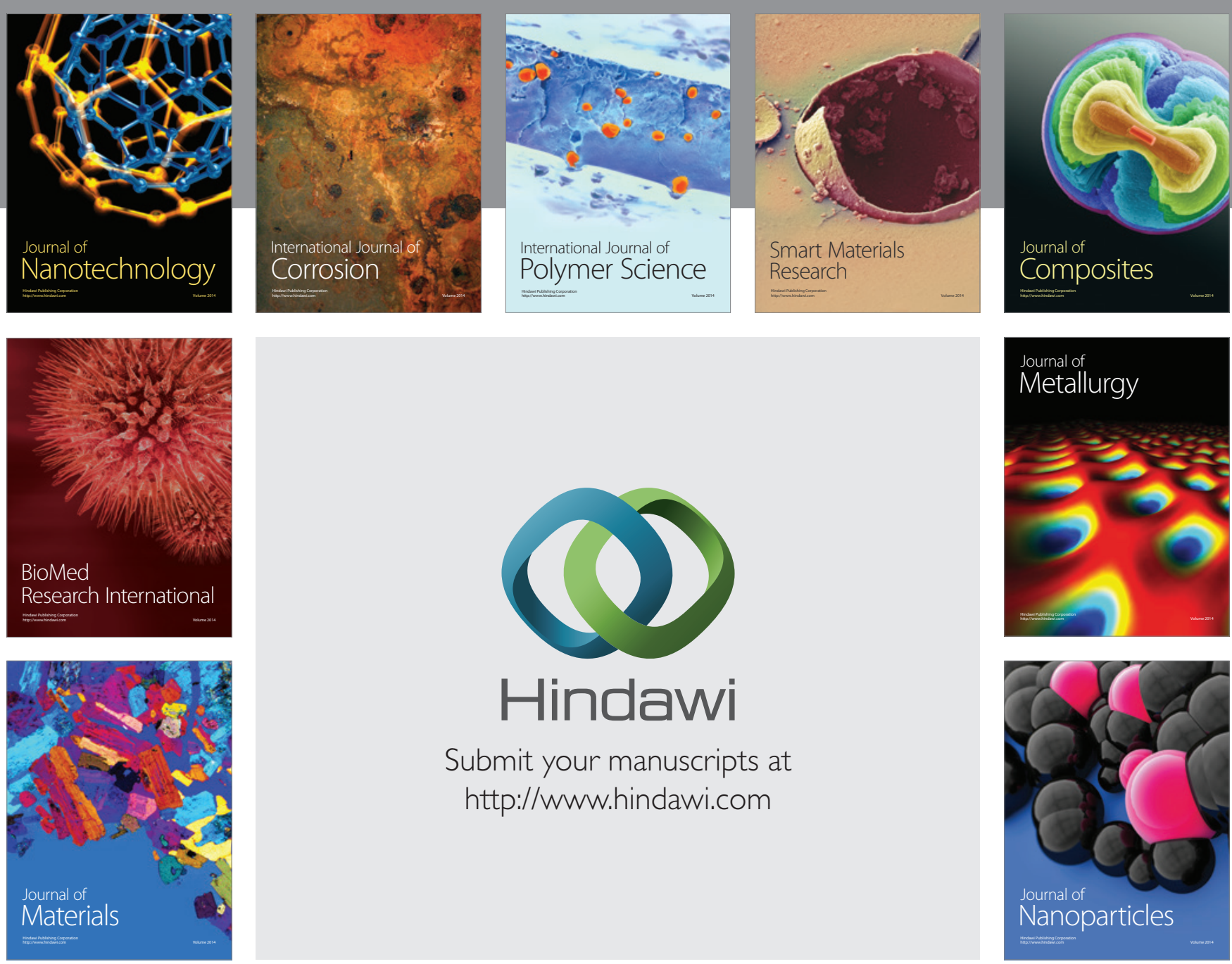

Submit your manuscripts at http://www.hindawi.com
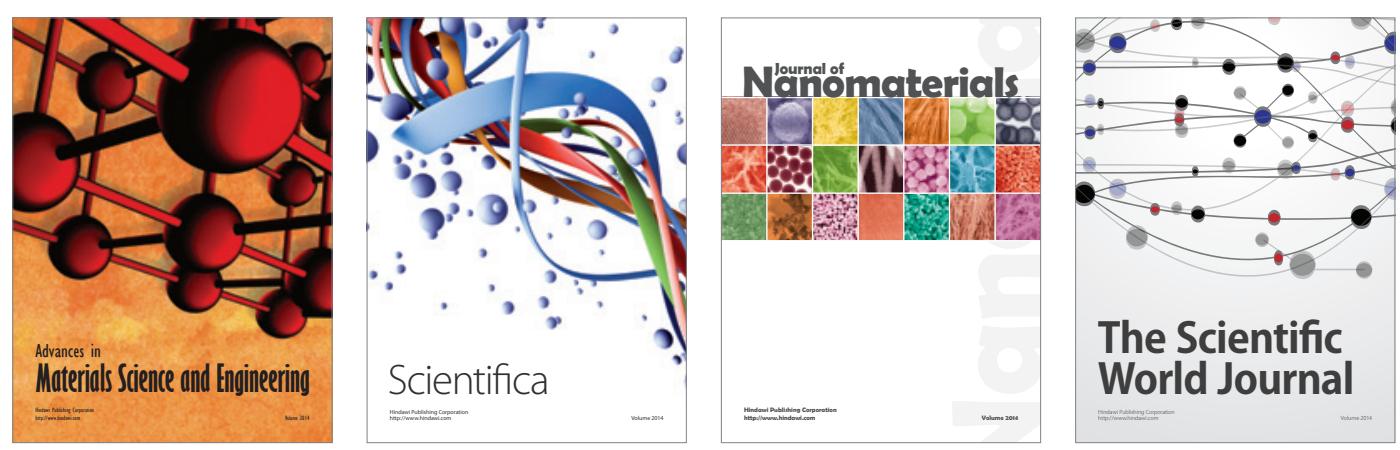

\section{The Scientific World Journal}
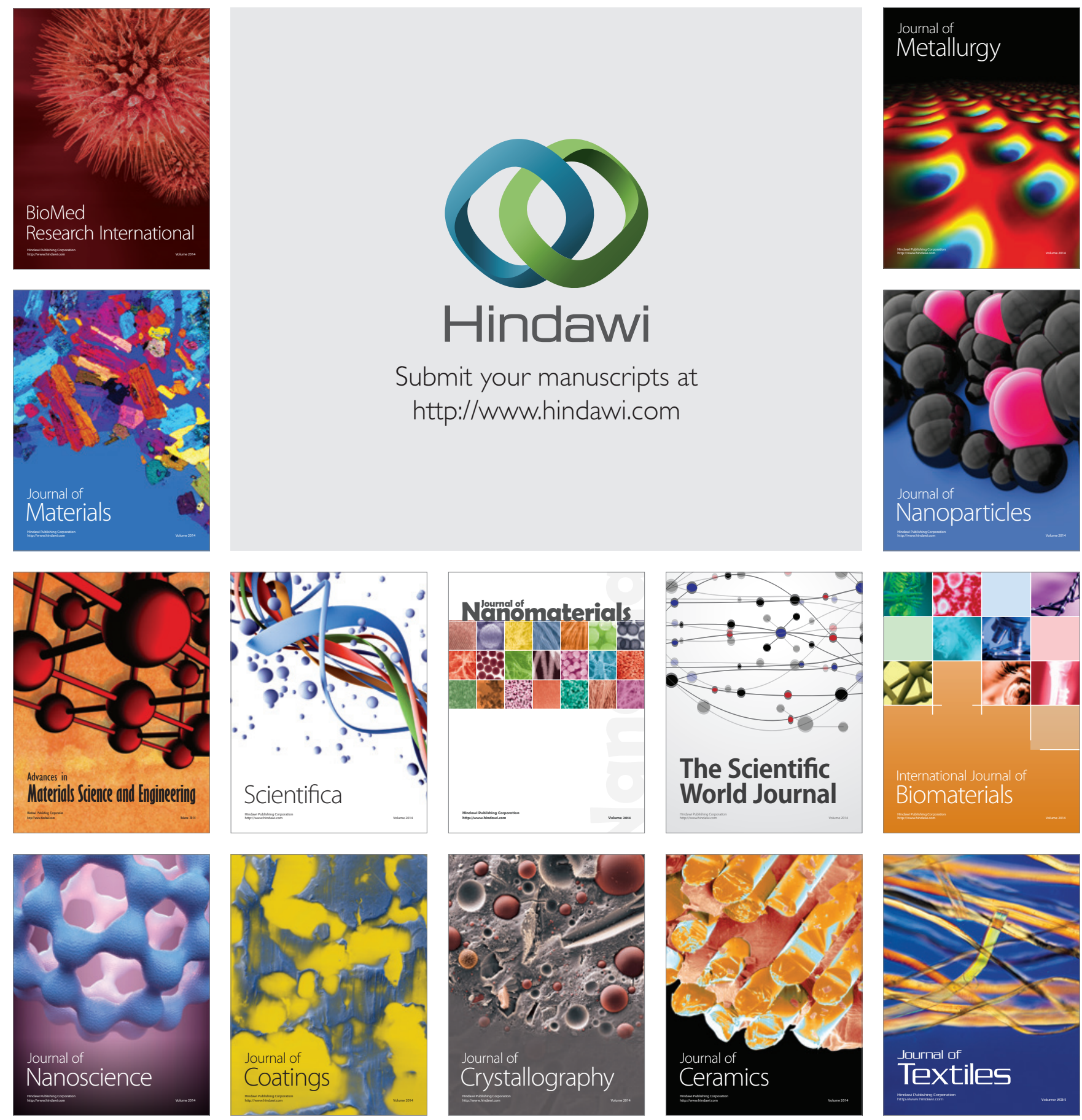